\title{
Does the Frequency of Watching Television Matters on Overweight and Obesity among Reproductive Age Women in Ethiopia?
}

\author{
Mohammed Ahmed $\left(D,{ }^{1}\right.$ Abdu Seid $\left(\mathbb{D},{ }^{2}\right.$ and Adnan Kemal ${ }^{3}$ \\ ${ }^{1}$ Epidemiology, Woldia University, Woldia, Ethiopia \\ ${ }^{2}$ Maternity and Reproductive Health Nursing, Woldia University, Woldia, Ethiopia \\ ${ }^{3}$ Human Nutrition, Defense University, Addis Ababa, Ethiopia \\ Correspondence should be addressed to Mohammed Ahmed; mohaasrar12@gmail.com
}

Received 16 March 2020; Revised 29 May 2020; Accepted 30 June 2020; Published 12 August 2020

Academic Editor: Eliot Brinton

Copyright (C) 2020 Mohammed Ahmed et al. This is an open access article distributed under the Creative Commons Attribution License, which permits unrestricted use, distribution, and reproduction in any medium, provided the original work is properly cited.

\begin{abstract}
Background. Studies in developed countries have revealed an association of different magnitudes between watching television and the risk of being overweight and obese among reproductive age women. Even so, there is no evidence of such an association in the context of the Ethiopian population. Hence, the study aimed to assess the association between watching television with overweight and obesity in a nationally representative sample of Ethiopian women. Methods. A cross-sectional study was conducted by using secondary data analysis from 2016 Ethiopia demographic and health survey among women aged from 15 to 49 years. The samples were selected using a two-stage stratified cluster sampling technique. A total of 10,074 women were included in the analysis. The outcome variables were both overweight and obesity, whereas the main exposure variable was the frequency of watching television. Multivariate logistic regression analysis was performed for adjusting potential confounders. Adjusted odds ratio (AOR) with $95 \%$ confidence intervals was used to declare a statistically significant association. Results. The study found that watching television at least once a week was significantly associated with both overweight (AOR: 1.79; 95\% CI: 1.20-2.73) and obesity (AOR: 3.76; 95\% CI: 2.04-6.95). The study also divulged that the odds of overweight were higher among women aged 25-39 years (AOR: 2.17; 95\% CI: 1.25-3.77) and 40-49 years (AOR: 2.69; 95\% CI: 1.45-5.00), urban residents (AOR: 1.76; 95\% CI:1.17-2.65), attended higher education (AOR:2.11; 95\% CI: 1.22-3.65), and richest in the wealth index (AOR: 2.83; 95\% CI:1.71-4.68). Similarly, the odds of obesity were higher among women aged 25-39 years and 40-49 years, attended higher education, and the richest in wealth index. Conclusions. The results from this study demonstrated that watching television at least once a week is associated with obesity among reproductive age women in Ethiopia. Therefore, a social behavioral change communication campaign needs to be taken to improve awareness regarding the harmful consequences of watching television for long hours. Further research studies should be conducted among men and adolescents to determine whether this positive association exists among that target population as well.
\end{abstract}

\section{Background}

Overweight and obesity are defined as abnormal or excessive fat accumulation that may impair health. Obesity is a worldwide public health problem, which affects both developed and developing countries [1]. Overweight and obesity are important risk factors for the development of noncommunicable diseases, including preeclampsia and eclampsia [2], cardiovascular diseases [3], hypertension [4], diabetes mellitus [5, 6], chronic kidney diseases [7], and cancer [8].
Reproductive aged women have higher rates of overweight and obesity and are more adversely affected by obesityrelated complications than men [9]. This gender discrepancy is mainly owed to general weight gain during pregnancy, childbearing years, adverse lifestyle, or risk factors associated with pregnancy and the postpartum period [10]. Maternal obesity increases the risk of copious complications, including a higher risk of cesarean delivery, a higher incidence of anesthetic and postoperative complications, low Apgar scores, macrosomia, and neural tube defects $[11,12]$. 
The association between watching television with overweight and obesity was evidenced by a different explanation such as hours spent in front of the television, decrease in the physical activity [13], a television-based food advertising influencing what and how people eat [14], and watching television leads to mindless eating or a lack of attention paid to consume due to external cues in the environment [15].

In the same vein, different studies revealed that watching television is positively associated with an overall increase in food intake [16, 17], particularly pizza [17], fast food, and highcalorie snacks [18] and is inversely associated with intakes of vegetables and fruits $[19,20]$. Similarly, young adults consumed more calories from energy-dense foods when watching television than when listening to classical music [17].

Various studies in different countries showed that watching television frequently was associated with overweight and obesity among reproductive aged women [21-24]. A previous study, which was conducted in Ethiopia, on the determinant of obesity and overweight among women [25] faced two drawbacks; first, the study was conducted without excluding women who gave birth in the last 2 months, which overestimated the prevalence of overweight and obesity as evidence showed that postpartum body weight is influenced by gestational weight gain and lactation $[26,27]$. Second, both overweight and obesity were analyzed as one outcome, merged during their analysis, which leads to misclassification of the outcomes. Therefore, the current study endeavored to fill this dearth by investigating whether there is an association between the frequency of watching television with overweight and obesity among reproductive age women.

\section{Methods}

2.1. Data Source and Sampling Procedure. The current study uses secondary data from the 2016 Ethiopia demographic and health survey (EDHS). A detailed description of the study design and methodology of the survey were founded elsewhere [28]. A two-stage stratified cluster sampling was used. Since Ethiopia has nine regional states and two city administrations, stratification was done by separating each structural division into urban and rural areas, except Addis Ababa (entirely urban). Therefore, a total of 23 sampling strata have been created. Then, each stratum was again further divided into enumeration areas (EAs) or clusters prepared by the 2007 Population and Housing Census as a sampling frame. In the first stage, a total of 645 EAs were selected. Of which, 202 were from urban areas. In the second stage, a fixed number of 28 households per cluster were selected randomly from the household listing. A total of 15,683 women (15-49 years) were interviewed, making up response rates of $95 \%$. The analytic sample for the current study consisted of women who were not pregnant and gave birth 2 months or more with a BMI of greater or equal to $18.5 \mathrm{Kg} / \mathrm{m}^{2}$ were included in the analysis $(n=10074)$.

2.2. Selection Criteria. The sample utilized in this study excluded (i) women who were pregnant at the time of the survey $(n=1122)$; (ii) women who gave birth less than 2 months preceding the date of the interview $(n=365)$; and (iii) women who had a BMI of less than $18.5 \mathrm{Kg} / \mathrm{m}^{2}$ $(n=4037)$ (Figure 1).

2.3. Study Variables. The dependent variables of this study had two outcomes (overweight and obesity) measured by body mass index (BMI), which is expressed as weight in kilogram divided by height in $\mathrm{m}^{2}$. EDHS carries out anthropometric measurements such as height and weight for women aged 15-49 years, excluding women who are pregnant and women who gave birth within 2 months preceding the date of the interview as an indicator of woman's nutritional status. As per WHO recommendations, the woman was categorized as normal when BMI was $18.5-24.9 \mathrm{~kg} / \mathrm{m}^{2}$, overweight if BMI was $25-29.9 \mathrm{~kg} / \mathrm{m}^{2}$, and obese if BMI was $\geq 30 \mathrm{~kg} / \mathrm{m}^{2}$.

The exposure variable of main interest was the frequency of watching television (TV), which was measured based on three categories (not watching television at all/watching television less than once a week/and watching television at least once a week).

Based on reviewing different literature, the following covariates were deemed relevant to the topic and for inclusion in the study such as the age of the respondents(15-24 years/25-39/40-49 years), residence (urban/rural), educational level (no education/primary/secondary/higher), marital status (never in union/currently in union/formerly in union), occupation (unemployed/nonagricultural/agricultural), wealth index (poorest/poorer/middle/richer/ richest), alcohol drinking(yes/no), and parity (one birth/2 to 4 births/greater than 4 births).

2.4. Data Analysis. The data were analyzed using SPSS version 20. All statistical procedures incorporated complex sampling design analysis applied in the 2016 EDHS. Frequencies and weighted percentages of the variables were utilized to describe the profile of the study participants. Rao-Scott adjusted chi-square statistic was used to examine the distribution between the outcome variables (overweight and obesity) and each of the independent variables. Multivariate logistic regression analysis was conducted to assess the association between watching television with overweight and obesity among women by adjusting the covariates. Adjusted odds ratios (AOR) with 95\% confidence interval were used to declare a statistically significant association.

\section{Results}

3.1. Participant's Characteristics. A total of 10,074 samples of reproductive age women were included and analyzed. About, $75.1 \%$ of respondents was rural residents, and $46.6 \%$ of the participants was found in the age between 25 and 39 years. Moreover, $46.8 \%$ of the respondents did not attend education. Only $17.5 \%$ of women watched television at least once per week. The prevalence of normal BMI, overweight, and obesity was $90.3 \%, 7.7 \%$, and $2.0 \%$, respectively (Table 1). 


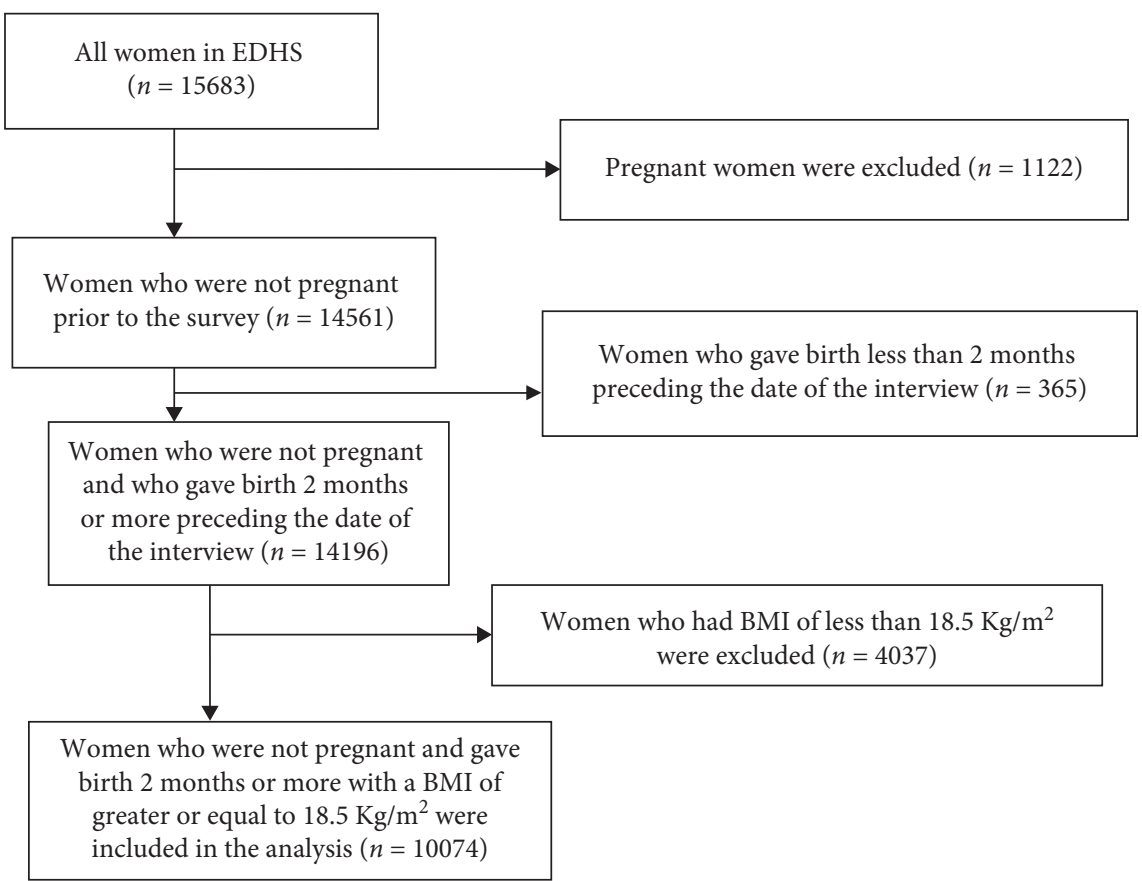

FIGURE 1: Flow chart showing the weighted sample used in the study.

TABLE 1: Sociodemographic characteristics of the study participants and the prevalence of overweight and obesity across the independent variables, EDHS $2016(n=10,074)$.

\begin{tabular}{|c|c|c|c|c|c|c|}
\hline \multirow[b]{2}{*}{ Variables } & \multirow[b]{2}{*}{ Category } & \multicolumn{4}{|c|}{ Body mass index (BMI) } & \multirow[b]{2}{*}{$p$ value } \\
\hline & & $\begin{array}{l}\text { Total } \\
n \text { (wt.\%) }\end{array}$ & $\begin{array}{l}\text { Normal } \\
n \text { (wt.\%) }\end{array}$ & $\begin{array}{c}\text { Overweight } \\
n \text { (wt.\%) }\end{array}$ & $\begin{array}{c}\text { Obese } \\
n \text { (wt.\%) }\end{array}$ & \\
\hline \multirow{3}{*}{ Age in years } & $15-24$ & $3867(37.7)$ & $3555(39.4)$ & $278(24.3)$ & $34(9.1)$ & \multirow{3}{*}{$<0.001^{*}$} \\
\hline & $25-39$ & $4581(46.6)$ & $3745(45.5)$ & $628(55.9)$ & $208(58.3)$ & \\
\hline & $40-49$ & $1626(15.7)$ & $1234(15.0)$ & $280(19.8)$ & $112(32.6)$ & \\
\hline \multirow{2}{*}{ Residence } & Urban & $3903(24.9)$ & $2746(20.7)$ & $861(59.6)$ & $296(82.8)$ & \multirow{2}{*}{$<0.001^{*}$} \\
\hline & Rural & $6171(75.1)$ & $5788(79.3)$ & $325(40.4)$ & $58(17.2)$ & \\
\hline \multirow{4}{*}{ Educational status } & No education & $4283(46.8)$ & $3863(48.7)$ & $334(31.5)$ & $86(19.1)$ & \multirow{4}{*}{$<0.001^{*}$} \\
\hline & Primary & $3427(34.6)$ & $2922(34.7)$ & $400(33.3)$ & $105(35.9)$ & \\
\hline & Secondary & $1531(12.6)$ & $1170(11.8)$ & $262(20.0)$ & $99(22.4)$ & \\
\hline & Higher & $833(5.9)$ & $579(4.8)$ & $190(15.3)$ & $64(22.6)$ & \\
\hline \multirow{3}{*}{ Marital status } & Never in union & $2846(26.9)$ & $2518(27.6)$ & $278(22.4)$ & $50(14.1)$ & \multirow{3}{*}{$<0.001^{*}$} \\
\hline & Currently in union & $6097(63.2)$ & $5136(63.1)$ & $717(63.5)$ & $244(67.3)$ & \\
\hline & Formerly in union & $1131(9.9)$ & $880(9.4)$ & $191(14.1)$ & $60(18.6)$ & \\
\hline \multirow{3}{*}{ Occupation } & Unemployed & $4800(47.4)$ & $4163(48.4)$ & $486(39.8)$ & $151(30.8)$ & \multirow{3}{*}{$<0.001^{*}$} \\
\hline & Nonagricultural & $3608(31.8)$ & $2784(29.3)$ & $634(52.1)$ & $190(65.5)$ & \\
\hline & Agricultural & $1666(20.8)$ & $1587(22.3)$ & $66(8.2)$ & $13(3.6)$ & \\
\hline \multirow{5}{*}{ Wealth index } & Poorest & $1974(15.0)$ & $1854(16.0)$ & $104(6.4)$ & $16(2.0)$ & \multirow{5}{*}{$<0.001^{*}$} \\
\hline & Poorer & $1250(17.0)$ & $1198(18.2)$ & $41(6.9)$ & $11(3.5)$ & \\
\hline & Middle & $1284(18.6)$ & $1228(20.0)$ & $50(7.9)$ & $6(0.4)$ & \\
\hline & Richer & $1386(20.0)$ & $1282(20.9)$ & $90(12.7)$ & $14(7.7)$ & \\
\hline & Richest & $4180(29.4)$ & $2972(25.0)$ & $901(66.2)$ & $307(86.3)$ & \\
\hline \multirow{3}{*}{ Parity } & 1 & $1224(16.8)$ & $991(16.7)$ & $182(19.2)$ & $51(14.3)$ & \multirow{3}{*}{$<0.001^{*}$} \\
\hline & $2-4$ & $2840(41.5)$ & $2251(40.3)$ & $417(48.2)$ & $172(64.4)$ & \\
\hline & $>4$ & $2490(41.6)$ & $2190(43.0)$ & $226(32.6)$ & $74(21.4)$ & \\
\hline \multirow{2}{*}{ Drank alcohol } & No & $6470(62.8)$ & $5525(63.2)$ & $735(60.5)$ & $210(56.6)$ & \multirow{2}{*}{0.25} \\
\hline & Yes & $3604(37.2)$ & $3009(36.8)$ & $451(39.5)$ & $144(43.4)$ & \\
\hline \multirow{3}{*}{ Frequency of watching television } & Not at all & $6038(69.9)$ & $5588(73.6)$ & $382(40.7)$ & $68(17.5)$ & \multirow{3}{*}{$<0.001^{*}$} \\
\hline & Less than once a week & $1251(12.6)$ & $1029(12.5)$ & $173(13.5)$ & $49(9.8)$ & \\
\hline & At least once a week & $2785(17.5)$ & $1917(13.9)$ & $631(45.8)$ & $237(72.7)$ & \\
\hline
\end{tabular}

$n$ : frequency; wt.\%: weight percentage; ${ }^{p} p$ value $<0.05$ is based on the adjusted $F$, which is a variant of the second-order Rao-Scott adjusted chi-square statistic. 
TABLE 2: Multivariate analysis of the association between the frequency of watching television and overweight and obesity among reproductive age women in Ethiopia.

\begin{tabular}{|c|c|c|c|c|c|}
\hline \multirow{2}{*}{ Variables } & \multirow{2}{*}{ Category } & \multicolumn{2}{|c|}{ Overweight } & \multicolumn{2}{|c|}{ Obesity } \\
\hline & & COR (95\% CI) & AOR (95\% CI) & COR $(95 \% \mathrm{CI})$ & AOR $(95 \% \mathrm{CI})$ \\
\hline \multirow{3}{*}{ Age in years } & $15-24$ & 1 & 1 & 1 & 1 \\
\hline & $25-39$ & $1.99(1.60-2.50)$ & $2.17(1.25-3.77)^{* *}$ & $5.57(2.92-10.6)$ & $13.8(5.47-34.9)^{* *}$ \\
\hline & $40-49$ & $2.13(1.64-2.78)$ & $2.69(1.45-5.00)^{* *}$ & $9.44(5.47-16.3)$ & $32.9(12.1-89.7)^{* *}$ \\
\hline \multirow{2}{*}{ Residence } & Urban & $5.64(4.30-7.40)$ & $1.76(1.17-2.65)^{* *}$ & $18.5(10.1-33.6)$ & $2.33(0.75-7.18)$ \\
\hline & Rural & 1 & 1 & 1 & 1 \\
\hline \multirow{4}{*}{ Educational status } & No education & 1 & 1 & 1 & 1 \\
\hline & Primary & $1.48(1.19-1.85)$ & $1.18(0.86-1.63)$ & $2.63(1.51-4.58)$ & $2.00(0.95-4.21)$ \\
\hline & Secondary & $2.62(1.96-3.50)$ & $1.47(0.89-2.43)$ & $4.84(2.85-8.21)$ & $2.02(0.95-4.28)$ \\
\hline & Higher & $4.95(3.48-7.02)$ & $2.11(1.22-3.65)^{* *}$ & $12.1(5.12-28.4)$ & $2.95(1.25-6.97)^{* *}$ \\
\hline \multirow{3}{*}{ Marital status } & Never in union & 1 & 1 & 1 & 1 \\
\hline & Married & $1.24(0.97-1.58)$ & $1.52(0.54-4.27)$ & $2.08(1.40-3.10)$ & $0.56(0.19-1.59)$ \\
\hline & Formerly in union & $1.85(1.34-2.57)$ & $1.79(0.63-5.15)$ & $3.88(2.28-6.60)$ & $0.72(0.21-2.45)$ \\
\hline \multirow{3}{*}{ Occupation } & Unemployed & 1 & 1 & 1 & 1 \\
\hline & Nonagricultural & $2.16(1.73-2.69)$ & $1.06(0.78-1.44)$ & $3.50(2.16-5.67)$ & $1.18(0.74-1.89)$ \\
\hline & Agricultural & $0.44(0.29-0.67)$ & $0.57(0.37-0.88)$ & $0.25(0.08-0.74)$ & $0.45(0.14-1.43)$ \\
\hline \multirow{5}{*}{ Wealth index } & Poorest & 1 & 1 & 1 & 1 \\
\hline & Poorer & $0.96(0.58-1.57)$ & $0.79(0.43-1.50)$ & $1.55(0.57-4.24)$ & $1.84(0.64-5.30)$ \\
\hline & Middle & $0.99(0.61-1.62)$ & $0.86(0.49-1.52)$ & $0.17(0.06-0.53)$ & $0.19(0.06-0.63$ \\
\hline & Richer & $1.53(0.99-2.37)$ & $1.26(0.73-2.17)$ & $2.93(1.07-8.06)$ & $2.19(0.76-6.40)$ \\
\hline & Richest & $6.69(4.60-9.72)$ & $2.83(1.71-4.68)^{* *}$ & $27.6(13.7-55.2)$ & $4.23(1.20-15.5)^{* *}$ \\
\hline \multirow{3}{*}{ Parity } & 1 & 1 & 1 & 1 & 1 \\
\hline & $2-4$ & $1.52(1.09-2.11)$ & $0.79(0.48-1.32)$ & $1.72(0.87-3.35)$ & $0.73(0.29-1.81)$ \\
\hline & $>4$ & $1.58(1.20-2.07)$ & $0.88(0.63-1.24)$ & $3.21(2.14-4.82)$ & $1.43(0.89-2.26)$ \\
\hline \multirow{2}{*}{ Drank alcohol } & No & 1 & 1 & 1 & 1 \\
\hline & Yes & $1.12(0.87-1.43)$ & $0.99(0.75-1.32)$ & $1.31(0.93-1.85)$ & $0.90(0.56-1.43)$ \\
\hline \multirow{3}{*}{ Watching television } & Not at all & 1 & 1 & 1 & 1 \\
\hline & Less than once a week & $1.94(1.41-2.66)$ & $1.04(0.63-1.73)$ & $3.28(1.66-6.49)$ & $1.76(0.78-3.95)$ \\
\hline & At least once a week & $5.95(4.68-7.56)$ & $1.79(1.20-2.73)^{* *}$ & $22.0(12.8-37.6)$ & $3.76(2.04-6.95)^{* *}$ \\
\hline
\end{tabular}

${ }^{* *}$ Significant association by AOR with $95 \%$ CI with a $p$ value of less than 0.05 .

\subsection{Factors Associated with Overweight and Obesity among} Reproductive Age Woman in Ethiopia. All the variables were entered into multivariate logistic regression analysis. After adjusting for potential confounders by logistic regression, watching television at least once per week, age of the respondents (25-39 and 40-49 years), urban residence, attending higher education, and being rich in wealth index were positively associated with overweight and obesity. The study found that the odds of overweight and obesity was 1.79 (AOR: 1.79; 95\% CI: 1.20-2.73) and 3.76 (AOR: 3.76; 95\% CI: 2.04-6.95) times higher among women watching television at least once a week compared to women not watched at all, respectively.

In this study, the odds of overweight were higher among woman aged 25-39 years (AOR: 2.17; 95\% CI: 1.25-3.77) and 40-49 years (AOR: 2.69; 95\% CI: 1.45-5.00), urban residents (AOR: 1.76; 95\% CI:1.17-2.6>5), attended higher education (AOR:2.11; 95\% CI: 1.22-3.65), and richest in wealth index (AOR: 2.83; 95\% CI:1.71-4.68). Likewise, the odds of obesity were higher among woman aged 25-39 years (AOR: 13.8; 95\% CI: 5.47-34.9) and 40-49 years (AOR: 32.9; 95\% CI: 12.1-89.7), attended higher education (AOR: 2.95; 95\% CI: 1.25-6.97), and richest in wealth index (AOR: 4.23; 95\% CI: 1.20-15.5) (Table 2).

\section{Discussion}

The study found that watching television at least once a week was significantly associated with both overweight and obesity among women of reproductive age in Ethiopia. The finding is coherent with studies conducted in the United States, Australia, Myanmar, Bangladesh, and India $[18,21-23,29]$. This may be due to watching television and displaces the physical activity, resulting in an overall decrease in energy expenditure [13].

The present study also showed that the odds of overweight were higher among women aged 25-39 years and 40-49 years, being urban residents, attending higher education, and richest in wealth index status. Likewise, the odds of obesity were also higher among woman aged 25-39 years and 40-49 years, attended higher education, and the richest in wealth index status.

The study has identified that the odds of overweight and obesity were higher among older women compared to younger women, which is consistent with findings from many other studies [30-33]. This may be explained by the intake of more energy-dense food as well as having less physical activity increases with age [34] and the association of higher age with changes in body composition (fat mass rises and also fat-free 
mass declines) $[35,36]$. Overweight was associated with being urban residents compared to its counterparts. This finding is consistent with studies performed in Bangladesh, Myanmar, Ghana, and India [21, 22, 37-39]. This may be due to highly developed transportation, and technology results employment to be less labor-consuming, and higher coverage of electricity in urban areas in comparison to rural areas exposes the women to watch television frequently, by decreasing the physical activity.

The highest educational qualification has a strong positive association with women being overweight and obese in this study, which is also consistent with findings from other similar studies $[30,33,40]$. The expected reason for this might be higher educational levels which lead a woman into more sedentary occupations resulting in less physical activity.

Moreover, being the richest in wealth index status was associated with both overweight and obesity. This finding is supported by studies conducted in Bangladesh and India [30-32]. This could be explained by the consumption of energy-dense food products and the intake of higher fat increases with the rise in income [41].

4.1. Strength and Limitation of the Study. As it was conducted on a national sample of Ethiopian women, the findings would contribute a lot to interventions aimed at preventing overweight and obesity, which is the risk factor for different noncommunicable diseases. The findings of this study have important implications for policymakers and other concerned bodies. However, there are some limitations to consider. First, as cross-sectional data were used, we cannot assign causations to any of the associations between the identified factors and the outcomes of interest.

\section{Conclusions}

From the finding of the study, it is possible to demonstrate that watching television is associated with obesity among reproductive aged women in Ethiopia. Therefore, a social behavioral change communication campaign needs to be taken to improve awareness regarding the harmful consequences of watching television for long hours. Further research should be conducted among men and adolescents to determine whether this positive association exists among that target population as well.

\section{Abbreviations}

AOR: Adjusted odds ratio

BMI: Body mass index

COR: Crude odds ratio

EDHS: Ethiopia demographic and health survey

SPSS: Statistical package for social science

TV: Television.

\section{Data Availability}

For this analysis, we used the USAID-DHS program 2016 Ethiopian demographic and health survey data set. To request the same or different data for another purpose, a new research project request should be submitted to the DHS program here: https://dhsprogram.com/data/AccessInstructions.cfm. The DHS program will normally review all data requests within 24-48 hours (during working days) and provide notification if access has been granted, or additional project information is needed before access can be granted. After receiving permission, the researcher can log in and select the specific data in the format they prefer.

\section{Ethical Approval}

The authors analyzed secondary data provided by 2016 Ethiopian demographic and health survey (EDHS). Ethical clearance for the EDHS 2016 data collection project was obtained from the ICF International's Institutional Review Board (IRB). The survey ensured international ethical standards of confidentiality, anonymity, and informed consent. This study is based on publicly available, deidentified DHS data.

\section{Conflicts of Interest}

The authors declare no potential conflicts of interest to the research, authorship, and publication of this article.

\section{Authors' Contributions}

MA conceived the research idea, conducted the data extraction, data analysis, and data interpretation, and wrote and reviewed the paper. AS and AK conducted data extraction and reviewed and approved the final manuscript. All authors have read and approved the manuscript.

\section{Acknowledgments}

The authors are grateful to the USAID-DHS program for providing access to 2016 Ethiopia demographic and health survey.

\section{References}

[1] WHO, Obesity and Overweight, WHO, Geneva, Switzerland, 2020, https://www.who.int/westernpacific/health-topics/ obesity.

[2] L. Kanguru, A. McCaw-Binns, J. Bell et al., "The burden of obesity in women of reproductive age and in pregnancy in a middle-income setting: a population based study from Jamaica," PLoS One, vol. 12, Article ID e0188677, 2017.

[3] P. Poirier, T. D. Giles, G. A. Bray et al., "Obesity and cardiovascular disease: pathophysiology, evaluation, and effect of weight loss," Circulation, vol. 113, no. 6, pp. 898-918, 2006.

[4] S.-Z. Jiang, W. Lu, X.-F. Zong, H.-Y. Ruan, and Y. Liu, "Obesity and hypertension," Experimental and Therapeutic Medicine, vol. 12, no. 4, pp. 2395-2399, 2016.

[5] A. Algoblan, M. Alalfi, and M. Khan, "Mechanism linking diabetes mellitus and obesity," Diabetes, Metabolic Syndrome and Obesity: Targets and Therapy, vol. 7, pp. 587-589, 2014.

[6] S. Y. Kim, L. England, H. G. Wilson, C. Bish, G. A. Satten, and P. Dietz, "Percentage of gestational diabetes mellitus attributable to overweight and obesity," American Journal of Public Health, vol. 100, no. 6, pp. 1047-1052, 2010. 
[7] C. P. Kovesdy, S. Furth, C. Zoccali et al., "Obesity and kidney disease: hidden consequences of the epidemic," Clinical Kidney Journal, vol. 10, no. 1, pp. 1-8, 2017.

[8] K. Basen-Engquist and M. Chang, "Obesity and cancer risk: recent review and evidence," Current Oncology Reports, vol. 13, no. 1, pp. 71-76, 2011.

[9] M. I. Cedergren, "Maternal morbid obesity and the risk of adverse pregnancy outcome," Obstetrics \& Gynecology, vol. 103, no. 2, pp. 219-224, 2004.

[10] E. P. Gunderson, "Childbearing and obesity in women: weight before, during, and after pregnancy," Obstetrics and Gynecology Clinics of North America, vol. 36, no. 2, pp. 317-332, 2009.

[11] F. Galtier-Dereure, C. Boegner, and J. Bringer, "Obesity and pregnancy: complications and cost," The American Journal of Clinical Nutrition, vol. 71, no. 5, pp. 1242S-1248S, 2000.

[12] S. Triunfo and A. Lanzone, "Impact of overweight and obesity on obstetric outcomes," Journal of Endocrinological Investigation, vol. 37, no. 4, pp. 323-329, 2014.

[13] R. H. DuRant, T. Baranowski, M. Johnson, and W. O. Thompson, "The relationship among television watching, physical activity, and body composition of young children," Pediatrics, vol. 94, no. 4, pp. 449-455, 1994.

[14] J. A. Foster, S. A. Gore, and D. S. West, "Altering TV viewing habits: an unexplored strategy for adult obesity intervention?" American Journal of Health Behavior, vol. 30, no. 1, pp. 3-14, 2006.

[15] B. Wansink, "From mindless eating to mindlessly eating better," Physiology \& Behavior, vol. 100, no. 5, pp. 454-463, 2010.

[16] F. Bellisle, A. M. Dalix, and G. Slama, "Non food-related environmental stimuli induce increased meal intake in healthy women: comparison of television viewing versus listening to a recorded story in laboratory settings," Appetite, vol. 43, no. 2, pp. 175-180, 2004.

[17] E. Blass, D. Anderson, H. Kirkorian, T. Pempek, I. Price, and M. Koleini, "On the road to obesity: television viewing increases intake of high-density foods," Physiology \& Behavior, vol. 88, no. 4-5, pp. 597-604, 2006.

[18] V. J. Cleland, M. D. Schmidt, T. Dwyer, and A. J. Venn, "Television viewing and abdominal obesity in young adults: is the association mediated by food and beverage consumption during viewing time or reduced leisure-time physical activity?" The American Journal of Clinical Nutrition, vol. 87, no. 5 , pp. 1148-1155, 2008.

[19] R. Boynton-Jarrett, T. N. Thomas, K. E. Peterson, J. Wiecha, A. M. Sobol, and S. L. Gortmaker, "Impact of television viewing patterns on fruit and vegetable consumption among adolescents," Pediatrics, vol. 112, no. 6, pp. 1321-1326, 2003.

[20] S. Feldman, M. E. Eisenberg, D. Neumark-Sztainer, and M. Story, "Associations between watching TV during family meals and dietary intake among adolescents," Journal of Nutrition Education and Behavior, vol. 39, no. 5, pp. 257-263, 2007.

[21] B. Ghose, "Frequency of TV viewing and prevalence of overweight and obesity among adult women in Bangladesh: a cross-sectional study," BMJ Open, vol. 7, no. 1, Article ID e014399, 2017.

[22] R. Das Gupta, I. H. Sajal, M. Hasan, I. Sutradhar, M. R. Haider, and M. Sarker, "Frequency of television viewing and association with overweight and obesity among women of the reproductive age group in Myanmar: results from a nationwide cross-sectional survey," BMJ Open, vol. 9, no. 3, Article ID e024680, 2019.
[23] R. Das Gupta, S. S. Haider, I. Sutradhar et al., “Association of frequency of television watching with overweight and obesity among women of reproductive age in India: evidence from a nationally representative study," PLoS One, vol. 14, no. 8, Article ID e0221758, 2019.

[24] M. A. B. Chowdhury, M. M. Adnan, and M. Z. Hassan, "Trends, prevalence and risk factors of overweight and obesity among women of reproductive age in Bangladesh: a pooled analysis of five national crosssectional surveys," BMJ Open, vol. 8, Article ID e018468, 2018.

[25] Y. Yeshaw, S. A. Kebede, A. M. Liyew et al., "Determinants of overweight/obesity among reproductive age group women in Ethiopia: multilevel analysis of Ethiopian demographic and health survey," BMJ Open, vol. 10, Article ID e034963, 2020.

[26] M. Haugen, L. B. Annie, W. Anna et al., "Associations of prepregnancy body mass index and gestational weight gain with pregnancy outcome and postpartum weight retention: a prospective observational cohort study," BMC Pregnancy and Childbirth, vol. 14, p. 201, 2014.

[27] P. Erica, Gunderson, and B. Abrams, "Epidemiology of gestational weight gain and body weight changes after pregnancy," Epidemiologic Reviews, vol. 22, no. 2, 2000.

[28] Central Statistical Agency (CSA), Ethiopia and ICF.Ethiopia Demographic and Health Survey 2016, Central Statistical Agency (CSA), Addis Ababa, Ethiopia, 2016.

[29] L. A. Tucker and M. Bagwell, "Television viewing and obesity in adult females," American Journal of Public Health, vol. 81, no. 7, pp. 908-911, 1991.

[30] H. Sarma, N. Saquib, M. M. Hasan et al., "Determinants of overweight or obesity among evermarried adult women in Bangladesh,” BMC Obesity, vol. 3, no. 1, p. 13, 2016.

[31] M. M. Khan and A. Krämer, "Factors associated with being underweight, overweight and obese among ever-married nonpregnant urban women in Bangladesh," Singapore Medical Journal, vol. 50, no. 8, p. 804, 2009.

[32] S. Subramanian, J. M. Perkins, and K. T. Khan, "Do burdens of underweight and overweight coexist among lower socioeconomic groups in India?" The American Journal of Clinical Nutrition, vol. 90, no. 2, pp. 369-376, 2009.

[33] S. Abrha, S. Shiferaw, and K. Y. Ahmed, "Overweight and obesity and its sociodemographic correlates among urban Ethiopian women: evidence from the 2011 EDHS," BMC Public Health, vol. 16, no. 1, p. 636, 2016.

[34] E. Alemu, A. Atnafu, M. Yitayal, and K. Yimam, "Prevalence of overweight and/or obesity and associated factors among high school adolescents in Arada sub city, Addis Ababa, Ethiopia," International Journal of Food Sciences and Nutrition, vol. 4, no. 2, p. 1, 2014.

[35] D. Gallagher, M. Visser, R. E. De Meersman et al., "Appendicular skeletal muscle mass: effects of age, gender, and ethnicity," Journal of Applied Physiology, vol. 83, no. 1, pp. 229-239, 1997.

[36] D. T. Villareal, C. M. Apovian, R. F. Kushner, and S. Klein, "Obesity in older adults: technical review and position statement of the American Society for Nutrition and NAASO, the Obesity Society," Obesity Research, vol. 13, no. 11, pp. 1849-1863, 2005.

[37] T. Biswas, M. J. Uddin, A. A. Mamun et al., "Increasing prevalence of overweight and obesity in Bangladeshi women of reproductive age: findings from 2004 to 2014," PLoS One, vol. 12, Article ID e0181080, 2017.

[38] R. Ofori-Asenso, A. A. Agyeman, A. Laar et al., "Overweight and obesity epidemic in Ghana-a systematic review and meta-analysis," BMC Public Health, vol. 16, p. 1239, 2016. 
[39] K. Gaur, K. Keshri, and W. Joe, "Does living in slums or nonslums influence women'l's nutritional status? Evidence from Indian mega-cities," Social Science \& Medicine, vol. 77, pp. 137-146, 2013.

[40] M. E. Hoque, K. Z. Long, L. W. Niessen, and A. A. Mamun, "Rapid shift toward overweight from double burden of underweight and overweight among Bangladeshi women: a systematic review and pooled analysis," Nutrition Reviews, vol. 73, no. 7, pp. 438-447, 2015.

[41] S. Du, T. A. Mroz, F. Zhai, and B. M. Popkin, "Rapid income growth adversely affects diet quality in China-particularly for the poor!" Social Science \& Medicine, vol. 59, no. 7, pp. 1505-1515, 2004. 